ISSN 0103-9954

\title{
ANÁLISE ECONÔMICA DA PRODUÇÃO DE Pinus elliottii NA SERRA DO SUDESTE, RIO GRANDE DO SUL
}

\author{
ECONOMIC ANALYSIS OF THE Pinus elliottii YIELD IN THE SOUTHEASTERN \\ MOUNTAIN RANGE, RIO GRANDE DO SUL
}

\author{
Eduardo Pagel Floriano ${ }^{1}$ Paulo Renato Schneider ${ }^{2}$ César Augusto G. Finger ${ }^{3}$ Frederico Dimas Fleig ${ }^{4}$
}

\section{RESUMO}

Este estudo foi realizado para Pinus elliottii Engelm. na Serra do Sudeste, Rio Grande do Sul, tendo como objetivos: determinar os custos de produção e receitas possíveis; realizar a análise econômica da produção de madeira nas condições regionais; determinar a rotação de máximo Valor Presente Líquido (VPL). Os custos de implantação dos povoamentos foram estimados em R $\$ 2.292,09 /$ ha e os de manutenção anual variaram de $\mathrm{R} \$ 134,84 /$ ha a $\mathrm{R} \$ 363,98 /$ ha. A partir do Índice de Sítio 28, com VPL de R\$ $1.147,17 /$ ha, a produção de madeira passa a ser economicamente interessante. No IS 26, com uma Taxa Interna de Retorno (TIR) de 6,86\% seria possível pagar juros de 6,75\% a.a. do Propflora. A análise de diferentes rotações para o IS 28 mostrou máximo VPL com rotação de 26 anos, desbastando em ciclo de 4 anos, iniciando-se os desbastes aos 10 anos. A análise econômica foi realizada com cautela, utilizando níveis de produtividade moderados, custos dentro de padrões que podem ser considerados entre médios e altos e preços comedidos para o atual mercado da madeira. Mesmo com as restrições impostas à análise, os resultados são promissores; especialmente tendo em vista a tendência de aumento dos preços no mercado regional e a probabilidade de indústrias laminadoras virem a absorver a produção de toras de maiores dimensões em um futuro próximo.

Palavras-chave: Pinus elliottii; produção; rentabilidade.

\begin{abstract}
This study was conducted for Pinus elliottii Engelm. at Serra do Sudeste, Rio Grande do Sul, with the following objectives: to check production costs and possible revenues; to perform the economic and financial analysis of Pinus elliottii's wood production under regional conditions; and to determine the rotation of maximum Net Present Value (NPV). The costs for planting the stands were estimated at $\$ 2,292.09 /$ ha and the annual maintenance ranged from $\mathrm{R} \$ 134.84$ to $\mathrm{R} \$ 363.98$ per hectare. Departing from the Site Index 28, with NPV of R \$1,147.17/ha, Pinus' wood production becomes interesting. At the IS 26, with $6.86 \%$ Internal Rate of Return (IRR), it would be possible to pay the $6.75 \%$ Propflora's interest. Analysis of different rotations for IS 28 showed maximum VPL with rotation of 26 years, thinning in cycle of 4 years, starting up the cuts to 10 years. The economic analysis was performed with considerable caution, using productivity moderated levels, costs within patterns that can be considered between middle and high and moderated prices for today's wood market. Even with the restrictions imposed on the analysis, results are promising; especially in view of the regional market prices' increase tendency and the probability of wood veneer industries comes to absorb the larger log's size production in a closed future.
\end{abstract}

Keywords: Pinus; yield; profitability.

1. Engenheiro Florestal, Dr., Professor Adjunto do Curso de Engenharia Florestal, Universidade Federal do Pampa, Campus de São Gabriel, Av. Antônio Trilha, 1847, CEP: 97300-000, São Gabriel (RS). edu.floriano@yahoo.com.br

2. Engenheiro Florestal, Dr., Professor Titular do Departamento de Ciências Florestais, Centro de Ciências Rurais, Universidade Federal de Santa Maria, Av. Roraima, 1000, CEP: 97105-900, Santa Maria (RS). paulors@smail.ufsm.br

3. Engenheiro Florestal, Dr., Professor Associado do Departamento de Ciências Florestais, Centro de Ciências Rurais, Universidade Federal de Santa Maria, Av. Roraima, 1000, CEP: 97105-900, Santa Maria (RS). finger@smail.ufsm.br

4. Engenheiro Florestal, Dr., Professor Adjunto do Departamento de Ciências Florestais, Centro de Ciências Rurais, Universidade Federal de Santa Maria, Av. Roraima, 1000, CEP: 97105-900, Santa Maria (RS). fdfleig@smail.ufsm.br

Recebido para publicação em 7/11/2008 e aceito em 14/10/2009. 


\section{INTRODUÇÃO}

A Mesorregião Metade Sul do Rio Grande do Sul apresenta múltiplos elementos estruturais socioeconômicos e históricos que se formaram baseados na utilização dos campos para a atividade de pecuária extensiva e rizicultura irrigada em terras de várzeas. É um espaço sub-regional inserido na região de fronteira entre o Brasil, o Uruguai e a Argentina.

A situação de depressão econômica da Metade Sul do RS e a oportunidade de desenvolvimento por meio da silvicultura, por diversos fatores integrados, são uma realidade que está sendo aproveitada pelo Governo, nos três níveis da administração, para impulsionar o desenvolvimento por meio de um grande programa regional. Como consequência, o incremento do número de investidores interessados em se instalar e ampliar suas atividades na região foi significativo. Em alguns casos, seu interesse foi concretizado em investimentos de grande porte.

As espécies mais promissoras para a região são o Eucalyptus saligna Smith, o Eucalyptus dunnii Maiden, o Pinus elliottii Engelm., o Pinus taeda L. e a Acacia mearnsii De Wild. Juntas, adaptam-se a uma infinidade de objetivos de produção e diferentes condições ambientais de cultivo. Dentre elas, o Pinus elliottii destaca-se como uma das espécies mais utilizadas em plantios comerciais no sul do Brasil, em conseqüência da semelhança das características ambientais com a região de origem no sudeste dos Estados Unidos. No RS, é usado na produção de madeira para móveis, construção civil e na produção de resina, utilizada em indústrias químicas, estando presente em vastas plantações por todo o leste do RS, incluindo a Serra do Sudeste, sendo que uma das espécies com maior área de plantio na região é o Pinus elliottii.

A viabilidade da silvicultura no Brasil vem sendo descoberta por lideranças de muitos estados e transformada em projetos concretos de governo. No dia 23 de abril de 2004, o Governo do estado do Rio Grande do Sul anunciou a liberação dos primeiros R\$ 30 milhões para o Programa de Financiamento Florestal Gaúcho (Proflora), com o objetivo de fomentar o florestamento para a "Metade Sul". Foi previsto o plantio de 120 mil hectares de florestas até 2006, agenciados pela CAIXA-RS e com apoio do Banco Nacional de Desenvolvimento Econômico e Social-BNDES. Essa fase se concretizou praticamente de forma integral e o programa de financiamento continua existindo, destinando-se a plantios de Pinus, Acacia mearnsii e Eucalyptus, abrangendo projetos de pessoas físicas e jurídicas de qualquer ramo de atividade, com um limite de financiamento anual de até $\mathrm{R} \$ 150$ mil por projeto individual, a uma taxa de juros de $6,75 \%$ a.a., sem correção monetária e prazo de amortização de até 12 anos, com carência de até 8 anos (CAIXA-RS, 2004; DIÁRIO POPULAR, 2004).

Além do financiamento, o Governo Estadual adotou um programa de incentivos fiscais para fomentar a indústria de base florestal. O objetivo principal foi acelerar o desenvolvimento da Metade Sul, criando uma cadeia produtiva capaz de gerar mais empregos, renda e impostos. Esses elementos são fundamentais para a melhoria das condições de vida da população da região considerada a menos desenvolvida do Estado (MI, 2003). A Metade Sul do RS é composta pelas regiões da Campanha, Depressão Central, Encosta do Sudeste, Litoral Sul e Serra do Sudeste.

Em 2000, o Brasil produziu cerca de 7,3 milhões de toneladas de produtos oriundos de madeira de Pinus. E, em 2005, só a produção de madeira serrada de Pinus atingiu 8,9 milhões de $\mathrm{m}^{3}$, quando havia 1,8 milhões de hectares de florestas de Pinus em território brasileiro, sendo 1,62 milhões de hectares para produção de celulose (SBS, 2006).

Além disso, o Brasil constitui-se no maior exportador mundial de madeira compensada de Pinus, tendo exportado cerca de 1,5 milhões de toneladas, ou 58\% da produção total de 2,6 milhões de toneladas, o que corresponde a $70 \%$ da produção nacional de compensados de Pinus. O consumo interno de compensados foi de 1,7 milhão $\mathrm{m}^{3}$.

Cerca de 3 mil empresas no Brasil, localizadas sobretudo nas regiões Sul e Sudeste, utilizam Pinus nos seus processos produtivos, concentrando-se nos seguintes produtos: indústria de madeira serrada, celulose e papel, painéis, compensados, MDF e OSB. O consumo dessas empresas vem aumentando e algumas produtoras de madeira de Pinus têm até mesmo abandonando o mercado externo para vender aqui. Em 2005, o consumo de madeira do segmento de celulose e papel foi de 46,9 milhões de $\mathrm{m}^{3}$ (39,8 milhões $\mathrm{m}^{3}$ de eucalipto e 7,1 milhões $\mathrm{m}^{3}$ de Pinus) dos quais cerca de $92 \%$ eram para processamento e o restante, para energia (ABRAF, 2006; SBS, 2006). 
Em 2005, os principais compradores da madeira serrada de Pinus foram os EUA, Espanha, Marrocos e México (ABIMCI, 2007).

A fabricação de produtos de maior valor agregado (PMVA), como madeira para construção e remanufaturados, molduras, beneficiados e pré-acabados (portas, janelas e torneados), armários e gabinetes semiacabados (banho, cozinha, tampos), móveis (domésticos, comerciais, jardim, institucionais), pallets e contêineres, estruturas e casas pré-fabricadas, está baseada especialmente na madeira de Pinus produzida no Sul e Sudeste e atingiu cerca de US\$ 1 bilhão em exportações em 2005 (ABIMCI, 2007).

O negócio "Silvicultura" parte da premissa de que existe mercado para seus produtos, como foi demonstrado nos parágrafos anteriores. Entretanto, poderá ser viável ou não participar dele, dependendo das muitas variáveis ou fatores envolvidos. Deve-se distinguir entre os fatores que levam à seleção de áreas para silvicultura, ou aqueles utilizados na análise da viabilidade de projetos silviculturais, ou dos utilizados para a seleção das espécies a cultivar nas áreas eleitas como adequadas à silvicultura. A viabilidade de projetos de investimento deve levar em conta os seguintes critérios: viabilidade técnica (engenharia), econômica, financeira, social e política (REZENDE, 2005).

A seleção de áreas para silvicultura deve basear-se nas características do terreno para sua implantação, uso atual e potencialidade de uso do solo, preço e dimensões da terra, aspectos ambientais, econômicos, políticos e sociais.

A sustentabilidade das atividades humanas tem sido questionada pela sociedade e passou a ser uma exigência. $\mathrm{O}$ manejo das florestas produtivas em regime sustentado vem sendo recomendado há cerca de três séculos pelos silvicultores e está impregnado na Engenharia Florestal desde que a primeira escola foi criada, tendo sido a primeira das atividades antrópicas a desenvolver um conceito de sustentabilidade. Conceito esse que vem evoluindo e, na atualidade, parte do princípio de que devem ser considerados os seus aspectos ambientais, sociais, e econômicos; esses três pilares formam a base da sustentabilidade do manejo florestal, de acordo a FAO (2007). Assim, qualquer análise de viabilidade de programas de desenvolvimento florestal deve considerá-los como prerrogativas.

Este estudo foi realizado para Pinus elliottii na Serra do Sudeste, Rio Grande do Sul, tendo como objetivos: determinar os custos de produção e receitas possíveis; realizar a análise econômica da produção de madeira nas condições regionais; determinar a rotação de máximo Valor Presente Líquido.

\section{MATERIAL E MÉTODOS}

\section{Local do estudo}

Os locais de estudo localizam-se nos municípios de Cachoeira do Sul e Encruzilhada do Sul, no Rio Grande do Sul, distando cerca de $140 \mathrm{~km}$ de Santa Maria e $200 \mathrm{~km}$ de Porto Alegre, com coordenadas geográficas entre $52^{\circ} 40^{\prime}$ e $53^{\circ} 00^{\prime}$ de longitude Oeste e entre $30^{\circ} 20^{\prime}$ e $30^{\circ} 45^{\prime}$ de latitude Sul.

\section{Características regionais}

As florestas estudadas são formados de Pinus elliottii entre 6 e 26 anos de idade e se encontram em áreas com características fisiográficas da Serra do Sudeste em sua encosta noroeste em direção à Depressão Central.

Os solos da região pertencem a três unidades: alissolos crômicos e hipocrômicos, neossolos litólicos e argilossolos acinzentados (EMBRAPA-SOLOS, 2006). A região tem relevo ondulado, dissecado em forma de colinas; com altitudes entre 200 e 400 metros acima do nível do mar.

$\mathrm{O}$ clima é subtropical úmido sem estação seca; a temperatura média anual fica em torno de $16^{\circ} \mathrm{C}$, a média do mês mais frio em torno de $12^{\circ} \mathrm{C}$ e a do mês mais quente em torno de $22^{\circ} \mathrm{C}$. A precipitação média anual está entre 1500 e $1600 \mathrm{~mm}$ (SCP, 2004), o que classifica o clima local como Cfb, pelo sistema de Köeppen, conforme Carvalho (1994).

\section{Rotação e ciclo de desbaste}

As florestas estudadas são manejadas em alto fuste para serraria, com plantio geralmente em espaçamento de $3 \times 2 \mathrm{~m}$, com três desramas realizadas em intervalo de 2 anos, iniciadas aos 5 anos, e quatro desbastes em ciclo de 4 anos, sendo o primeiro aos 10 anos de idade e rotação de 26 anos. Os cálculos foram realizados para todos os Índices de Sítio que não foram considerados fora do padrão regional. Dentre 
eles, procurou-se identificar o sítio com produtividade mais próxima da realidade local, condizente com a média nacional de $25 \mathrm{~m}^{3} \cdot \mathrm{ha}^{-1}$. ano $\mathrm{o}^{-1}$ e que apresentasse viabilidade econômica para servir de base de estudo e comparação. Após a identificação do Índice de Sítio para base de comparação, foi determinada a rotação de máximo Valor Presente Líquido entre 18 e 30 anos, com desbastes iniciando aos 10 anos de idade e ciclo de desbaste de 4 anos.

\section{Custos e rendimentos na cultura de Pinus}

Os custos da silvicultura e os rendimentos operacionais foram obtidos de diversas fontes na região, sobretudo de empresas prestadoras de serviços, silvicultoras e cooperativas agrícolas que se dispuseram a colaborar com esta pesquisa. Na maioria dos casos, houve a solicitação de não identificação da fonte; portanto, nenhuma fonte de dados econômicos ou silviculturais foi identificada neste trabalho.

Os cálculos de custos foram realizados com base nos preços cobrados por empresas prestadoras de serviços florestais e preços de produtos no segundo semestre de 2007.

É prática geral calcular o valor dos custos administrativos como $10 \%$ dos custos operacionais. Neste trabalho, foram discriminados alguns custos administrativos como o monitoramento das florestas e o monitoramento de pragas, doenças, matocompetição e aceiros. Consequentemente, reduziu-se o restante para $8 \%$ dos custos operacionais.

Nos cálculos dos valores anuais, somaram-se os custos de arrendamento praticados na região para a área de pecuária, o que é o mais comum. O valor gira em torno de $50 \mathrm{~kg}$ de boi vivo por hectare, cotados a $\mathrm{R} \$ 2,40 / \mathrm{kg}$, dando um total de R $\$ 120,00 /$ ha por ano, tendo-se adotado esse valor nos cálculos. O valor mínimo de arrendamento é de cerca de $40 \mathrm{~kg}$ de boi vivo por hectare, cotados a $\mathrm{R} \$ 2,10 / \mathrm{kg}$, dando um total de $\mathrm{R} \$ 84,00 /$ ha por ano.

Algumas operações como capina e combate às formigas não são necessárias sobre todas as áreas em todos os anos. Foi estimado um percentual de incidência sobre a área total para as operações em que se julgou o conhecimento empírico como suficientemente preciso, pois não se obteve registro dessas operações. Na maioria das operações, a incidência foi considerada sobre $100 \%$ da área. Os preços, rendimentos e incidência sobre a área total utilizados nos cálculos são discriminados nas Tabelas 1 a 14 . O custo anual em Reais é encontrado multiplicando-se a incidência pelo rendimento e pelo preço das tabelas anexas.

\section{Silvicultura regional de Pinus}

Conforme os dados levantados, as práticas silviculturais mais comuns observadas foram adotadas como metodologia para efeito deste trabalho, conforme se descreve a seguir.

A silvicultura na região inicia com o planejamento e licenciamento da área, marcação de estradas e aceiros e delimitação das áreas de reserva legal e preservação permanente.

Em seguida, deve ser realizada a abertura das estradas principais, o que pode ser executado com tratores de esteira ou motoniveladoras. Os solos da região têm boa agregação e capacidade de suporte, não sendo necessários tratamentos da superfície das estradas na implantação; o rendimento na abertura das estradas atinge em torno de $30 \mathrm{~m}$ lineares por hora com tratores de esteira de 12 a $14 \mathrm{t}$ com lâmina frontal. 
TABELA 1: Custos de implantação de florestas de Pinus na Serra do Sudeste, RS (2007).

TABLE 1: Establishment costs of Pinus forests at Serra do Sudeste. RS (2007).

\begin{tabular}{|c|c|c|c|c|c|}
\hline Operação & Centro de custo & Unidade & $\begin{array}{c}\text { Incidência } \\
\%\end{array}$ & $\begin{array}{c}\text { Rendimento/ } \\
\text { unidade }\end{array}$ & $\begin{array}{c}\text { Preço } \\
\mathrm{R} \$\end{array}$ \\
\hline Administração geral & $8 \%$ dos custos operacionais & $\%$ aa & 100,00 & 0,08 & $2.011,20$ \\
\hline Arrendamento & $50 \mathrm{~kg}$ boi vivo / ha / ano & $\mathrm{R} \$$ & 100,00 & 50,00 & 2,40 \\
\hline Topografia & Serviços de topografia & ha & 100,00 & 1,00 & 9,00 \\
\hline $\begin{array}{l}\text { Elaboração do projeto e orientação da } \\
\text { implantação }\end{array}$ & Serviços de engenharia & ha & 100,00 & 1,00 & 40,00 \\
\hline $\begin{array}{l}\text { Demarcação da rede viária, de áreas de } \\
\text { preservação e reserva legal }\end{array}$ & Mão-de-obra & $\mathrm{h}$ & 100,00 & 0,15 & 12,56 \\
\hline $\begin{array}{l}\text { Demarcação da rede viária, de áreas de } \\
\text { preservação e reserva legal }\end{array}$ & $\begin{array}{l}\text { Trator de pneu médio com } \\
\text { sulcador }\end{array}$ & $\mathrm{h}$ & 100,00 & 0,10 & 65,00 \\
\hline Construção da rede viária & Trator de esteiras médio & $\mathrm{h}$ & 100,00 & 1,67 & 125,00 \\
\hline Limpeza de terreno & Pá-carregadeira & $\mathrm{h}$ & 100,00 & 0,20 & 85,00 \\
\hline Combate às formigas pré-plantio & Mão-de-obra & $\mathrm{h}$ & 100,00 & 3,00 & 4,38 \\
\hline Combate às formigas pré-plantio & Isca formicida & $\mathrm{kg}$ & 100,00 & 5,00 & 6,64 \\
\hline Herbicida pós-emergente & Glifosato (1/3 da área) & 1 & 100,00 & 1,20 & 13,20 \\
\hline Herbicida pós-emergente & Trator de pneus médio & $\mathrm{h}$ & 100,00 & 1,50 & 65,00 \\
\hline Roçada mecanizada na entrelinha & Trator de pneus leve & $\mathrm{h}$ & 100,00 & 1,70 & 45,00 \\
\hline Preparo de solo sulcamento & Trator de esteira D50 & $\mathrm{h}$ & 100,00 & 3,00 & 110,00 \\
\hline Aquisição das mudas & Mudas & mil & 100,00 & 1,67 & 230,00 \\
\hline Transporte das mudas & Transporte & mil & 100,00 & 1,67 & 10,00 \\
\hline Plantio das mudas & Mão-de-obra & $\mathrm{h}$ & 100,00 & 12,50 & 4,38 \\
\hline Plantio das mudas & Trator de pneu leve & $\mathrm{h}$ & 100,00 & 1,50 & 38,00 \\
\hline Combate às formigas no plantio & Mão-de-obra & $\mathrm{h}$ & 100,00 & 3,00 & 4,38 \\
\hline Combate às formigas no plantio & Isca formicida & $\mathrm{kg}$ & 100,00 & 3,00 & 6,64 \\
\hline Herbicida pré-emergente & Produto (1/3 da área) & 1 & 100,00 & 1,00 & 115,98 \\
\hline Herbicida pré-emergente & Trator de pneus médio & $\mathrm{h}$ & 100,00 & 1,50 & 53,00 \\
\hline Aquisição das mudas replantio (5\%) & Mudas & mil & 100,00 & 0,08 & 230,00 \\
\hline Transporte das mudas replantio & Transporte & mil & 100,00 & 1,67 & 10,00 \\
\hline Plantio das mudas replantio & Mão-de-obra & $\mathrm{h}$ & 100,00 & 5,00 & 4,38 \\
\hline Combate às formigas sistemático, repasse 1 & Mão-de-obra & $\mathrm{h}$ & 100,00 & 1,50 & 4,38 \\
\hline Combate às formigas sistemático, repasse 1 & Isca formicida & $\mathrm{kg}$ & 100,00 & 2,00 & 6,64 \\
\hline Coroamento & Mão-de-obra & ha & 100,00 & 1,00 & 143,26 \\
\hline Roçada mecanizada na entrelinha & Trator de pneus leve & $\mathrm{h}$ & 70,00 & 1,70 & 45,00 \\
\hline Combate às formigas sistemático, repasse 2 & Mão-de-obra & $\mathrm{h}$ & 100,00 & 1,50 & 4,38 \\
\hline Combate às formigas sistemático, repasse 2 & Isca formicida & $\mathrm{kg}$ & 100,00 & 2,00 & 6,64 \\
\hline Coroamento & Mão-de-obra & ha & 80,00 & 1,00 & 111,43 \\
\hline Roçada mecanizada na entrelinha & Trator de pneus leve & $\mathrm{h}$ & 50,00 & 1,70 & 45,00 \\
\hline
\end{tabular}

Após a limpeza do terreno é necessário combater as formigas com isca formicida a base de sulfluramida na dose de $5 \mathrm{~kg} / \mathrm{ha}$ antes do plantio e de $3 \mathrm{~kg} /$ ha durante o plantio, com repasses aos 30 e 120 dias após o plantio na dose de $2 \mathrm{~kg} / \mathrm{ha}$.

$\mathrm{Na}$ implantação das florestas, é realizada, com antecedência de 7 a 10 dias do plantio das mudas, a aplicação de 3 a 4 litros por hectare de herbicida glifosato (pós-emergente) na linha de plantio e, imediatamente após o plantio, pode-se aplicar 3 litros por hectare de herbicida pré-emergente para manter a floresta jovem livre de matocompetição durante cerca de 120 dias. A aplicação de herbicidas é realizada numa faixa com um metro de largura, atingindo $1 / 3$ da área; nos $2 / 3$ restantes é realizada roçada mecanizada.

Assim que o herbicida apresenta o efeito desejado, é executado o preparo de solo com subsolagem na profundidade de 50 a $60 \mathrm{~cm}$, com trator de esteiras de $130 \mathrm{CV}$. Pela falta de comprovação da eficiência ou mesmo da necessidade de adubação, e em se considerando que o efeito da adubação sobre os Pinus é muito pequena, não sendo praticada na região por ser considerada dispendiosa, não participou da composição dos custos neste trabalho. 
TABELA 2: Custos de manutenção do $1^{\circ}$ ano de florestas de Pinus na Serra do Sudeste, RS (2007). TABLE 2: Costs of $1^{\text {st }}$ year maintenance for Pinus forests at Serra do Sudeste, RS (2007).

\begin{tabular}{|c|c|c|c|c|c|}
\hline Operação & Centro de custo & Unidade & $\begin{array}{c}\text { Incidência } \\
\%\end{array}$ & $\begin{array}{l}\text { Rendimento } \\
\text { por unidade }\end{array}$ & \begin{tabular}{|c|} 
Preço \\
R\$
\end{tabular} \\
\hline Administração geral & $8 \%$ dos custos operacionais & $\%$ aa & 100,00 & 0,08 & 225,90 \\
\hline Arrendamento & $50 \mathrm{~kg}$ boi vivo / ha por ano & $\mathrm{R} \$$ & 100,00 & 50,00 & 2,40 \\
\hline Combate às formigas sistemático & Mão-de-obra & $\mathrm{h}$ & 80,00 & 1,50 & 4,38 \\
\hline Combate às formigas sistemático & Isca formicida & $\mathrm{kg}$ & 80,00 & 2,00 & 6,64 \\
\hline Coroamento & Mão-de-obra & ha & 60,00 & 1,00 & 143,26 \\
\hline Roçada mecanizada na entrelinha & Trator de pneus leve & $\mathrm{h}$ & 30,00 & 1,70 & 45,00 \\
\hline Monitoramento de ervas daninhas, pragas e doenças & Mão-de-obra & $\mathrm{h}$ & 100,00 & 0,05 & 12,56 \\
\hline Monitoramento de ervas daninhas, pragas e doenças & Motocicleta & $\mathrm{h}$ & 100,00 & 0,05 & 10,00 \\
\hline Combate às formigas sistemático & Mão-de-obra & $\mathrm{h}$ & 70,00 & 1,50 & 4,38 \\
\hline Combate às formigas sistemático & Isca formicida & $\mathrm{kg}$ & 70,00 & 2,00 & 6,64 \\
\hline Coroamento & Mão-de-obra & ha & 40,00 & 1,00 & 143,26 \\
\hline Roçada mecanizada na entrelinha & Trator de pneus leve & $\mathrm{h}$ & 20,00 & 1,70 & 45,00 \\
\hline Roçada mecanizada de aceiros & Trator de pneus leve & $\mathrm{h}$ & 10,00 & 3,00 & 45,00 \\
\hline
\end{tabular}

TABELA 3: Custos de manutenção do $2^{\circ}$ ano de florestas de Pinus na Serra do Sudeste, RS (2007). TABLE 3: Costs of $2^{\text {nd }}$ year maintenance for Pinus forests at Serra do Sudeste, RS (2007).

\begin{tabular}{|c|c|c|c|c|c|}
\hline Operação & Centro de custo & Unidade & $\begin{array}{l}\text { Incidência } \\
\%\end{array}$ & $\begin{array}{l}\text { Rendimento } \\
\text { por unidade }\end{array}$ & $\begin{array}{l}\text { Preço } \\
\mathrm{R} \$\end{array}$ \\
\hline Administração geral & $8 \%$ dos custos operacionais & $\%$ aa & 100,00 & 0,08 & 182,35 \\
\hline Arrendamento & $50 \mathrm{~kg}$ boi vivo / ha por ano & $\mathrm{R} \$$ & 100,00 & 50,00 & 2,40 \\
\hline $\begin{array}{l}\text { Monitoramento de aceiros, ervas daninhas, } \\
\text { pragas e doenças }\end{array}$ & Mão-de-obra & $\mathrm{h}$ & 100,00 & 0,05 & 12,56 \\
\hline $\begin{array}{l}\text { Monitoramento de aceiros, ervas daninhas, } \\
\text { pragas e doencas }\end{array}$ & Motocicleta & $\mathrm{h}$ & 100,00 & 0,05 & 10,00 \\
\hline Combate às formigas sistemático & Mão-de-obra & $\mathrm{h}$ & 70,00 & 1,50 & 4,38 \\
\hline Combate às formigas sistemático & Isca formicida & $\mathrm{kg}$ & 70,00 & 2,00 & 6,64 \\
\hline Coroamento & Mão-de-obra & ha & 70,00 & 1,00 & 143,26 \\
\hline Roçada mecanizada na entrelinha & Trator de pneus leve & $\mathrm{h}$ & 70,00 & 1,70 & 45,00 \\
\hline Roçada mecanizada de aceiros & Trator de pneus leve & $\mathrm{h}$ & 10,00 & 3,00 & 45,00 \\
\hline
\end{tabular}

TABELA 4: Custos de manutenção do $3^{\circ}$ ano de florestas de Pinus na Serra do Sudeste, RS (2007).

TABLE 4: Costs of $3^{\text {rd }}$ year maintenance for Pinus forests at Serra do Sudeste, RS (2007).

\begin{tabular}{|c|c|c|c|c|c|}
\hline Operação & Centro de custo & Unidade & $\begin{array}{c}\text { Incidência } \\
\%\end{array}$ & $\begin{array}{l}\text { Rendimento } \\
\text { por unidade }\end{array}$ & $\begin{array}{c}\text { Preço } \\
\text { R\$ }\end{array}$ \\
\hline & custos & & & & \\
\hline Administração geral & operacionais & $\%$ aa & 100,00 & 0,08 & 134,43 \\
\hline Arrendamento & $50 \mathrm{~kg}$ boi vivo / ha por ano & $\mathrm{R} \$$ & 100,00 & 50,00 & 2,40 \\
\hline Monitoramento de ervas daninhas, pragas e doenças & Mão-de-obra & $\mathrm{h}$ & 100,00 & 0,05 & 12,56 \\
\hline Monitoramento de ervas daninhas, pragas e doenças & Motocicleta & $\mathrm{h}$ & 100,00 & 0,05 & 10,00 \\
\hline Combate às formigas sistemático & Mão-de-obra & $\mathrm{h}$ & 50,00 & 1,50 & 4,38 \\
\hline Combate às formigas sistemático & Isca formicida & $\mathrm{kg}$ & 50,00 & 2,00 & 6,64 \\
\hline Coroamento & Mão-de-obra & ha & 50,00 & 1,00 & 143,26 \\
\hline Roçada mecanizada na entrelinha & Trator de pneus leve & $\mathrm{h}$ & 50,00 & 1,70 & 45,00 \\
\hline Roçada mecanizada de aceiros & Trator de pneus leve & $\mathrm{h}$ & 10,00 & 3,00 & 45,00 \\
\hline
\end{tabular}


TABELA 5: Custos de manutenção geral - anos 4, 11, 12, 13, 15, 16, 17, 19, 20, 21, 23, 24 e 25 - florestas de Pinus na Serra do Sudeste, RS (2007).

TABLE 5: Costs of general maintenance - year 4, 11, 12, 13, 15, 16, 17, 19, 20, 21, 23, 24 e 25 - for Pinus forests at Serra do Sudeste, RS (2007).

\begin{tabular}{|c|c|c|c|c|c|}
\hline Operação & Centro de custo & Unidade & $\begin{array}{c}\text { Incidência } \\
\%\end{array}$ & $\begin{array}{l}\text { Rendimento } \\
\text { por unidade }\end{array}$ & $\begin{array}{c}\text { Preço } \\
\text { R\$ }\end{array}$ \\
\hline Administração geral & $8 \%$ dos custos operacionais & $\%$ aa & 100,00 & 0,08 & 13,74 \\
\hline Arrendamento & $50 \mathrm{~kg}$ boi vivo / ha por ano & $\mathrm{R} \$$ & 100,00 & 50,00 & 2,40 \\
\hline Monitoramento de aceiros, pragas e doenças & Mão-de-obra & $\mathrm{h}$ & 100,00 & 0,00 & 12,56 \\
\hline Monitoramento de aceiros, pragas e doenças & Motocicleta & $\mathrm{h}$ & 100,00 & 0,00 & 10,00 \\
\hline Combate às formigas sistemático & Mão-de-obra & $\mathrm{h}$ & 35,00 & 1,50 & 4,38 \\
\hline Combate às formigas sistemático & Isca formicida & $\mathrm{kg}$ & 35,00 & 2,00 & 6,64 \\
\hline Roçada mecanizada de aceiros & Trator de pneus leve & $\mathrm{h}$ & 5,00 & 3,00 & 45,00 \\
\hline
\end{tabular}

TABELA 6: Custos de $1^{\underline{a}}$ desrama - $5^{0}$ ano - florestas de Pinus na Serra do Sudeste, RS (2007).

TABLE 6: Costs of $1^{\text {st }}$ pruning $-5^{\text {th }}$ year - Pinus forests at Serra do Sudeste, RS (2007).

\begin{tabular}{l|l|c|c|r|r}
\hline Operação & \multicolumn{1}{|c|}{ Centro de custo } & Unidade & $\begin{array}{c}\text { Incidência } \\
\%\end{array}$ & $\begin{array}{c}\text { Rendimento } \\
\text { por unidade }\end{array}$ & \multicolumn{1}{c}{$\begin{array}{c}\text { Preço } \\
\text { R\$ }\end{array}$} \\
\hline Administração geral & 8\% dos custos operacionais & $\%$ aa & 100,00 & 0,08 & 218,86 \\
Arrendamento & 50 kg boi vivo / ha por ano & $\mathrm{R} \$$ & 100,00 & 50,00 & 2,40 \\
Monitoramento de aceiros, pragas e doenças & Mão-de-obra & $\mathrm{h}$ & 100,00 & 0,00 & 12,56 \\
Monitoramento de aceiros, pragas e doenças & Motocicleta & $\mathrm{h}$ & 100,00 & 0,00 & 10,00 \\
Combate às formigas sistemático & Mão-de-obra & $\mathrm{h}$ & 35,00 & 1,50 & 45,00 \\
Combate às formigas sistemático & Isca formicida & $\mathrm{kg}$ & 35,00 & 2,00 & 6,64 \\
Roçada mecanizada de aceiros & Trator de pneus leve & $\mathrm{h}$ & 5,00 & 3,00 & 45,00 \\
Desrama até 2,5 m & Mão-de-obra & ha & 100,00 & 1,00 & 183,79 \\
\hline
\end{tabular}

TABELA 7: Custos de manutenção do $6^{0}$ ano de florestas de Pinus na Serra do Sudeste, RS (2007).

TABLE 7: Costs of maintenance of $6^{\text {th }}$ year for Pinus forests at Serra do Sudeste, RS (2007).

\begin{tabular}{|c|c|c|c|c|c|}
\hline Operação & Centro de custo & Unidade & $\begin{array}{c}\text { Incidência } \\
\%\end{array}$ & $\begin{array}{l}\text { Rendimento } \\
\text { por unidade }\end{array}$ & $\begin{array}{c}\text { Preço } \\
\text { R\$ }\end{array}$ \\
\hline Administração geral & $8 \%$ dos custos operacionais & $\%$ aa & 100,00 & 0,08 & 34,40 \\
\hline Arrendamento & $50 \mathrm{~kg}$ boi vivo / ha por ano & $\mathrm{R} \$$ & 100,00 & 50,00 & 2,40 \\
\hline Monitoramento de aceiros, pragas e doenças & Mão-de-obra & $\mathrm{h}$ & 100,00 & 0,00 & 12,56 \\
\hline Monitoramento de aceiros, pragas e doenças & Motocicleta & $\mathrm{h}$ & 100,00 & 0,00 & 10,00 \\
\hline Combate às formigas sistemático & Mão-de-obra & $\mathrm{h}$ & 35,00 & 1,50 & 4,38 \\
\hline Combate às formigas sistemático & Isca formicida & $\mathrm{kg}$ & 35,00 & 2,00 & 6,64 \\
\hline Roçada mecanizada de aceiros & Trator de pneus leve & $\mathrm{h}$ & 5,00 & 3,00 & 45,00 \\
\hline Inventário florestal & Mão-de-obra operária & $\mathrm{h}$ & 100,00 & 1,00 & 4,38 \\
\hline Inventário florestal & Mão-de-obra técnica & ha & 100,00 & 0,50 & 12,56 \\
\hline Inventário florestal & Serviços de engenharia & ha & 100,00 & 1,00 & 10,00 \\
\hline
\end{tabular}

TABELA 8: Custos de $2^{\mathrm{a}}$ desrama $-7^{\mathrm{o}}$ ano - florestas de Pinus na Serra do Sudeste, RS (2007).

TABLE 8: Costs of $2^{\text {nd }}$ pruning $-7^{\text {th }}$ year - Pinus forests at Serra do Sudeste, RS (2007).

\begin{tabular}{|c|c|c|c|c|c|}
\hline Operação & Centro de custo & Unidade & $\begin{array}{c}\text { Incidência } \\
\%\end{array}$ & $\begin{array}{l}\text { Rendimento } \\
\text { por unidade }\end{array}$ & $\begin{array}{c}\text { Preço } \\
\mathrm{R} \$\end{array}$ \\
\hline Administração geral & $8 \%$ dos custos operacionais & $\%$ aa & 100,00 & 0,08 & 209,49 \\
\hline Arrendamento & $50 \mathrm{~kg}$ boi vivo / ha por ano & $\mathrm{R} \$$ & 100,00 & 50,00 & 2,40 \\
\hline Monitoramento de aceiros, pragas e doenças & Mão-de-obra & $\mathrm{h}$ & 100,00 & 0,00 & 12,56 \\
\hline Monitoramento de aceiros, pragas e doenças & Motocicleta & $\mathrm{h}$ & 100,00 & 0,00 & 10,00 \\
\hline Combate às formigas sistemático & Mão-de-obra & $\mathrm{h}$ & 35,00 & 1,50 & 4,38 \\
\hline Combate às formigas sistemático & Isca formicida & $\mathrm{kg}$ & 35,00 & 2,00 & 6,64 \\
\hline Roçada mecanizada de aceiros & Trator de pneus leve & $\mathrm{h}$ & 5,00 & 3,00 & 45,00 \\
\hline Desrama até $2,5 \mathrm{~m}$ & Mão-de-obra & ha & 100,00 & 1,00 & 195,75 \\
\hline
\end{tabular}


TABELA 9: Custos de manutenção do $8^{\circ}$ ano de florestas de Pinus na Serra do Sudeste, RS (2007). TABLE 9: Costs of maintenance of $8^{\text {th }}$ year for Pinus forests at Serra do Sudeste, RS (2007).

\begin{tabular}{|c|c|c|c|c|c|}
\hline Operação & Centro de custo & Unidade & $\begin{array}{c}\text { Incidência } \\
\%\end{array}$ & $\begin{array}{l}\text { Rendimento } \\
\text { por unidade }\end{array}$ & $\begin{array}{l}\text { Preço } \\
\text { R\$ }\end{array}$ \\
\hline Administração geral & $8 \%$ dos custos operacionais & $\%$ aa & 100,00 & 0,08 & 55,72 \\
\hline Arrendamento & $50 \mathrm{~kg}$ boi vivo / ha por ano & $\mathrm{R} \$$ & 100,00 & 50,00 & 2,40 \\
\hline Monitoramento de aceiros, pragas e doenças & Mão-de-obra & $\mathrm{h}$ & 100,00 & 0,00 & 12,56 \\
\hline Monitoramento de aceiros, pragas e doenças & Motocicleta & $\mathrm{h}$ & 100,00 & 0,00 & 10,00 \\
\hline Combate às formigas sistemático & Mão-de-obra & $\mathrm{h}$ & 35,00 & 1,50 & 45,00 \\
\hline Combate às formigas sistemático & Isca formicida & $\mathrm{kg}$ & 35,00 & 2,00 & 6,64 \\
\hline Roçada mecanizada de aceiros & Trator de pneus leve & $\mathrm{h}$ & 5,00 & 3,00 & 45,00 \\
\hline Inventário florestal & Mão-de-obra operária & $\mathrm{h}$ & 100,00 & 1,00 & 4,38 \\
\hline Inventário florestal & Mão-de-obra técnica & ha & 100,00 & 0,50 & 12,56 \\
\hline Inventário florestal & Serviços de engenharia & ha & 100,00 & 1,00 & 10,00 \\
\hline
\end{tabular}

TABELA 10: Custos de $3^{\underline{a}}$ desrama $-9^{0}$ ano - florestas de Pinus na Serra do Sudeste, RS (2007).

TABLE 10: Costs of $3^{\text {rd }}$ pruning $-9^{\text {th }}$ year - Pinus forests at Serra do Sudeste, RS (2007).

\begin{tabular}{|c|c|c|c|c|c|}
\hline Operação & Centro de custo & Unidade & $\begin{array}{c}\text { Incidência } \\
\%\end{array}$ & $\begin{array}{l}\text { Rendimento } \\
\text { por unidade }\end{array}$ & $\begin{array}{c}\text { Preço } \\
\text { R\$ }\end{array}$ \\
\hline Administração geral & $8 \%$ dos custos operacionais & $\%$ aa & 100,00 & 0,08 & 261,69 \\
\hline Arrendamento & $50 \mathrm{~kg}$ boi vivo / ha por ano & $\mathrm{R} \$$ & 100,00 & 50,00 & 2,40 \\
\hline Monitoramento de aceiros, pragas e doenças & Mão-de-obra & $\mathrm{h}$ & 100,00 & 0,00 & 12,56 \\
\hline Monitoramento de aceiros, pragas e doenças & Motocicleta & $\mathrm{h}$ & 100,00 & 0,00 & 10,00 \\
\hline Combate às formigas sistemático & Mão-de-obra & $\mathrm{h}$ & 35,00 & 1,50 & 4,38 \\
\hline Combate às formigas sistemático & Isca formicida & $\mathrm{kg}$ & 35,00 & 2,00 & 6,64 \\
\hline Roçada mecanizada de aceiros & Trator de pneus leve & $\mathrm{h}$ & 5,00 & 3,00 & 45,00 \\
\hline Desrama até $2,5 \mathrm{~m}$ & Mão-de-obra & ha & 100,00 & 1,00 & 247,95 \\
\hline
\end{tabular}

TABELA 11: Custos de manutenção pré-desbaste - anos 10, 14, 18 E 22 - florestas de Pinus na Serra do Sudeste, RS (2007).

TABLE 11: Costs of maintenance pre-thinning - year 10,14, 18 and 22 - Pinus forests at Serra do Sudeste, RS (2007).

\begin{tabular}{|c|c|c|c|c|c|}
\hline Operação & Centro de custo & Unidade & $\begin{array}{l}\text { Incidência } \\
\%\end{array}$ & $\begin{array}{l}\text { Rendimento } \\
\text { por unidade }\end{array}$ & $\begin{array}{c}\text { Preço } \\
\mathrm{R} \$\end{array}$ \\
\hline Administração geral & $8 \%$ dos custos operacionais & $\%$ aa & 100,00 & 0,08 & 19,40 \\
\hline Arrendamento & $50 \mathrm{~kg}$ boi vivo / ha por ano & $\mathrm{R} \$$ & 100,00 & 50,00 & 2,40 \\
\hline Monitoramento de aceiros, pragas e doenças & Mão-de-obra & $\mathrm{h}$ & 100,00 & 0,00 & 12,56 \\
\hline Monitoramento de aceiros, pragas e doenças & Motocicleta & $\mathrm{h}$ & 100,00 & 0,00 & 10,00 \\
\hline Combate às formigas sistemático & Mão-de-obra & $\mathrm{h}$ & 35,00 & 1,50 & 4,38 \\
\hline Combate às formigas sistemático & Isca formicida & $\mathrm{kg}$ & 35,00 & 2,00 & 6,64 \\
\hline Manutenção de estradas e aceiros ( $5 \mathrm{~m}$ x $50 \mathrm{~m} / \mathrm{ha})$ & Motoniveladora & $\mathrm{h}$ & 100,00 & 0,15 & 80,00 \\
\hline $\begin{array}{l}\text { Inventário florestal pré-corte (somente áreas a } \\
\text { desbastar) }\end{array}$ & Mão-de-obra operária & $\mathrm{h}$ & 1,00 & 1,00 & 4,38 \\
\hline $\begin{array}{l}\text { Inventário florestal pré-corte (somente áreas a } \\
\text { desbastar) }\end{array}$ & Mão-de-obra técnica & ha & 1,00 & 0,50 & 12,56 \\
\hline $\begin{array}{l}\text { Inventário florestal pré-corte (somente áreas a } \\
\text { desbastar) }\end{array}$ & Serviços de engenharia & ha & 1,00 & 1,00 & 10,00 \\
\hline $\begin{array}{l}\text { Inventário florestal pós-corte (somente áreas } \\
\text { desbastadas) }\end{array}$ & Mão-de-obra operária & $\mathrm{h}$ & 1,00 & 1,00 & 4,38 \\
\hline $\begin{array}{l}\text { Inventário florestal pós-corte (somente áreas } \\
\text { desbastadas) }\end{array}$ & Mão-de-obra técnica & ha & 1,00 & 0,50 & 12,56 \\
\hline $\begin{array}{l}\text { Inventário florestal pós-corte (somente áreas } \\
\text { desbastadas) }\end{array}$ & Serviços de engenharia & ha & 1,00 & 1,00 & 10,00 \\
\hline
\end{tabular}


TABELA 12: Custos de desbastes de florestas de Pinus na Serra do Sudeste, RS (2007). TABLE 12: Costs of thinning for Pinus forests at Serra do Sudeste, RS (2007).

\begin{tabular}{l|l|c|c|c|c}
\hline Operação & \multicolumn{1}{|c|}{ Centro de custo } & Unidade & $\begin{array}{c}\text { Incidência } \\
\%\end{array}$ & $\begin{array}{c}\text { Rendimento } \\
\text { por unidade }\end{array}$ & $\begin{array}{c}\text { Preço } \\
\mathrm{R} \$\end{array}$ \\
\hline Administração do desbaste & 8\% dos custos operacionais & $\%$ aa & 100,00 & 0,08 & 19,02 \\
Desbaste & Corte, processo embandeiramento & $\mathrm{m}^{3}$ & 100,00 & 1,00 & 12,92 \\
Baldeio & Carga, baldeio e descarga na pilha & $\mathrm{m}^{3}$ & 100,00 & 1,00 & 2,79 \\
Carregamento & Carregamento para transporte & $\mathrm{m}^{3}$ & 100,00 & 1,00 & 3,30 \\
\hline
\end{tabular}

TABELA 13: Custos de manutenção pré-colheita - 26ํㅜ ano - florestas de Pinus na Serra do Sudeste, RS (2007).

TABLE 13: Costs of maintenance pre-harvest $-26^{\text {th }}$ year - Pinus forests in the Serra do Sudeste, RS (2007).

\begin{tabular}{l|l|r|r|r|r}
\hline Operação & \multicolumn{1}{c|}{ Centro de custo } & Unidade & $\begin{array}{c}\text { Incidência } \\
\%\end{array}$ & $\begin{array}{r}\text { Rendimento } \\
\text { por unidade }\end{array}$ & \multicolumn{1}{c}{$\begin{array}{c}\text { Preço } \\
\text { R } \$\end{array}$} \\
\hline Administração geral & 8\% dos custos operacionais & $\%$ aa & 100,00 & 0,08 & 104,63 \\
Arrendamento & 50 kg boi vivo / ha por ano & $\mathrm{R} \$$ & 100,00 & 50,00 & 2,40 \\
Roçada pré-corte mecanizada na entrelinha & Trator de pneus leve & $\mathrm{h}$ & 20,00 & 1,70 & 143,26 \\
Combate às formigas pré-corte & Mão-de-obra & $\mathrm{h}$ & 100,00 & 3,00 & 4,38 \\
Combate às formigas pré-corte & Isca formicida & $\mathrm{kg}$ & 100,00 & 5,00 & 6,64 \\
Manutenção de estradas e aceiros (5m x & Motoniveladora & $\mathrm{h}$ & 80,00 & 0,15 & 80,00 \\
$50 \mathrm{~m} / \mathrm{ha}$ ) & & & &
\end{tabular}

TABELA 14: Custos de colheita de florestas de Pinus na Serra do Sudeste, RS (2007).

TABLE 14: Costs of harvesting Pinus forests at Serra do Sudeste, RS (2007).

\begin{tabular}{|c|c|c|c|c|c|}
\hline Operação & Centro de custo & Unidade & $\begin{array}{c}\text { Incidência } \\
\%\end{array}$ & $\begin{array}{l}\text { Rendimento } \\
\text { por unidade }\end{array}$ & $\begin{array}{l}\text { Preço } \\
\mathrm{R} \$\end{array}$ \\
\hline Administração da colheita & $8 \%$ dos custos operacionais & $\%$ aa & 100,00 & 0,08 & 14,36 \\
\hline Inventário florestal (somente áreas a colher) & Mão-de-obra operária & $\mathrm{h}$ & 0,35 & 1,00 & 4,38 \\
\hline Inventário florestal (somente áreas a colher) & Mão-de-obra técnica & ha & 0,35 & 0,50 & 12,56 \\
\hline Inventário florestal (somente áreas a colher) & Serviços de engenharia & ha & 0,35 & 1,00 & 10,00 \\
\hline Corte raso & $\begin{array}{l}\text { Corte, processo e } \\
\text { embandeiramento }\end{array}$ & $\mathrm{m}^{3}$ & 100,00 & 1,00 & 9,99 \\
\hline Baldeio & Carga, baldeio e descarga na pilha & $\mathrm{m}^{3}$ & 100,00 & 1,00 & 2,69 \\
\hline Carregamento & Carregamento para transporte & $\mathrm{m}^{3}$ & 100,00 & 1,00 & 1,61 \\
\hline
\end{tabular}

Adotou-se o espaçamento de plantio de $3 \mathrm{~m}$ entre linhas e de $2 \mathrm{~m}$ entre plantas na linha como o mais comum, ou densidade de 1.667 plantas por hectare.

Na sequência, vêm os 3 primeiros anos de manutenção, durante os quais as plantações têm de ser mantidas livres de mato-competição por meio de roçada ou capina na entrelinha no caso de infestação por ervas de folhas largas ou de gramíneas, respectivamente, sendo que a capina pode ser manual ou mecanizada, física ou química, com aplicação realizada com pulverizador costal na linha de plantio e mecanizada na entrelinha, devendo-se realizar monitoramento de ervas daninhas para determinar a necessidade da operação. Neste trabalho, optou-se por coroamento manual das plantas e roçada ou capina mecanizada na entrelinha para reduzir o impacto ambiental, o que tem sido sugerido por auditores na certificação pelo FSC (IMAFLORA/SMARTWOOD, 2004). As formigas devem ser mantidas sob controle e o combate realizado somente se o monitoramento acusar necessidade; quando isso ocorrer, deve ser realizada aplicação sistemática de $2 \mathrm{~kg} /$ ha de formicida granulado nas áreas infestadas, que podem chegar a $70 \%$ do total, nessa fase; posteriormente, até o corte final, deve ser realizado monitoramento para determinar a ocorrência de pontos de concentração de alta infestação que devam ser combatidos; embora as formigas não causem prejuízo após os 3-4 anos de idade do povoamento, áreas infestadas podem ser focos para infestação de outros locais; o combate pode ser necessário em cerca de $20 \%$ das áreas nesse período.

A partir do $5^{\circ}$ ano após o plantio, são iniciadas as desramas, que são executadas no $5^{\circ}, 7^{\circ}$ e $9^{\circ}$ anos. Os desbastes são iniciados, em geral, no $10^{\circ}$ ano. O intervalo de corte entre desbastes pode variar de 3 a 5 anos. A rotação dos Pinus na Região Sul varia entre 20 e 30 anos, quando se procede ao corte raso da floresta e sua renovação. A regeneração natural dos Pinus é intensa, mas em razão da pouca seleção 
genética dos plantios velhos existentes, as empresas têm preferido renovar as plantações por mudas de qualidade superior.

\section{RESULTADOS E DISCUSSÃO}

\section{Custos da produção de madeira}

Os custos calculados por fase são resumidos na Tabela 15. Os valores encontrados estão próximos aos de outros estudos, relacionados em secções anteriores. Na implantação foram encontrados valores de US\$ 400,00 (cerca de R $\$ 720,00$ com dólar cotado a $\mathrm{R} \$ 1,80$ ) até próximo de $\mathrm{R} \$ 3.000,00$, mas esses extremos parecem fora da realidade. Valores entre $\mathrm{R} \$ 1.000,00$ até $\mathrm{R} \$ 2.500,00$ para a implantação de 1 hectare de florestas, dependendo da situação, parecem ser coerentes. Valores próximos aos que foram calculados neste estudo são: R \$ 2.000,00 em São Paulo (SILVA, 2005), R \$ 2.000,00 no Mato Grosso do Sul (JOVEM SUL NEWS, 2006), R\$ 2.103,19 (BOLETIM FLORESTAL, dez/2007) e R $2.306,85$ (BRDE, 2003).

TABELA 15: Custos por fase na produção de madeira de Pinus na Serra do Sudeste, RS (2007).

TABLE 15: Cost by phase for Pinus' wood production at Serra do Sudeste, RS (2007).

\begin{tabular}{|c|c|c|}
\hline Fase & Custo (R\$/ha) & Custo $\left(\mathrm{R} \$ / \mathrm{m}^{3}\right)$ \\
\hline$\overline{\text { Implantação - Ano } 0}$ & $2.292,09$ & - \\
\hline Manutenção do $1^{\underline{0}}$ ano & 363,98 & - \\
\hline Manutenção do $2^{\underline{0}}$ ano & 316,94 & - \\
\hline Manutenção do $3^{\mathbf{0}}$ ano & 265,18 & - \\
\hline Manutenção geral & 134,84 & - \\
\hline $1^{\mathrm{a}}$ Desrama & 356,36 & - \\
\hline Manutenção 6 & 157,15 & - \\
\hline $2^{2}$ Desrama 2 & 346,25 & - \\
\hline Manutenção 8 & 180,18 & - \\
\hline $3^{3}$ Desrama 3 & 402,63 & - \\
\hline Manutenção pré-desbaste & 140,96 & - \\
\hline Manutenção pré-colheita & 233,00 & - \\
\hline Desbastes & - & 20,54 \\
\hline Colheita & - & 15,51 \\
\hline
\end{tabular}

\section{Produção}

As prognoses de produção foram baseadas nas Tabelas Dinâmicas de Produção elaboradas por Floriano (2008). A produção total acumulada por hectare variou de $528 \mathrm{~m}^{3}$ no Sítio 22, até $1140 \mathrm{~m}^{3}$ no Sítio 34, ou seja, mais do que o dobro um do outro. As produções previstas por sítio e por intervenção são apresentadas na Figura 1. O Incremento médio anual ao final da rotação mostra que, nos povoamentos com Índices de Sítio inferior a 26, a produtividade é baixa, inferior à média brasileira de $25 \mathrm{~m}^{3} \cdot \mathrm{ha}^{-1}$.ano ${ }^{-1}$ informada pelo Banco do Brasil (2005), ABRAF (2006) e SBS (2006). As prognoses para os povoamentos com Índices de Sítio 30 e acima, entretanto, ultrapassam a média de $32,3 \mathrm{~m}^{3} \cdot$ ha $^{-1}$.ano ${ }^{-1}$ obtida pela Klabin no Paraná de acordo com Bernett (2006).

\section{Estimativas de receitas}

As receitas não atualizadas, previstas com a venda da madeira em pé, foram calculadas pelo produto do volume estimado a ser produzido $\mathrm{em}^{3}$ multiplicado pelo valor em Reais por $\mathrm{m}^{3}$ de madeira de cada sortimento. Os sortimentos foram classificados de acordo com o diâmetro na ponta fina das toras ou toretes conforme os critérios a seguir:

- Toretes para processo - diâmetro entre $\geq 7 \mathrm{~cm} \mathrm{e}<12 \mathrm{~cm}$ na ponta fina - R $\$ 19,00 / \mathrm{m}^{3}$;

- Tora fina - diâmetro entre $\geq 12 \mathrm{~cm} \mathrm{e}<17 \mathrm{~cm}$ na ponta fina- $\mathrm{R} \$ 25,35 / \mathrm{m}^{3}$;

- Tora média - diâmetro entre $\geq 17 \mathrm{~cm} \mathrm{e}<23 \mathrm{~cm}$ na ponta fina - R $\$ 29,00 / \mathrm{m}^{3}$;

- Tora grossa - diâmetro $\geq 23 \mathrm{~cm}$ na ponta fina $-\mathrm{R} \$ 44,00 / \mathrm{m}^{3}$. 


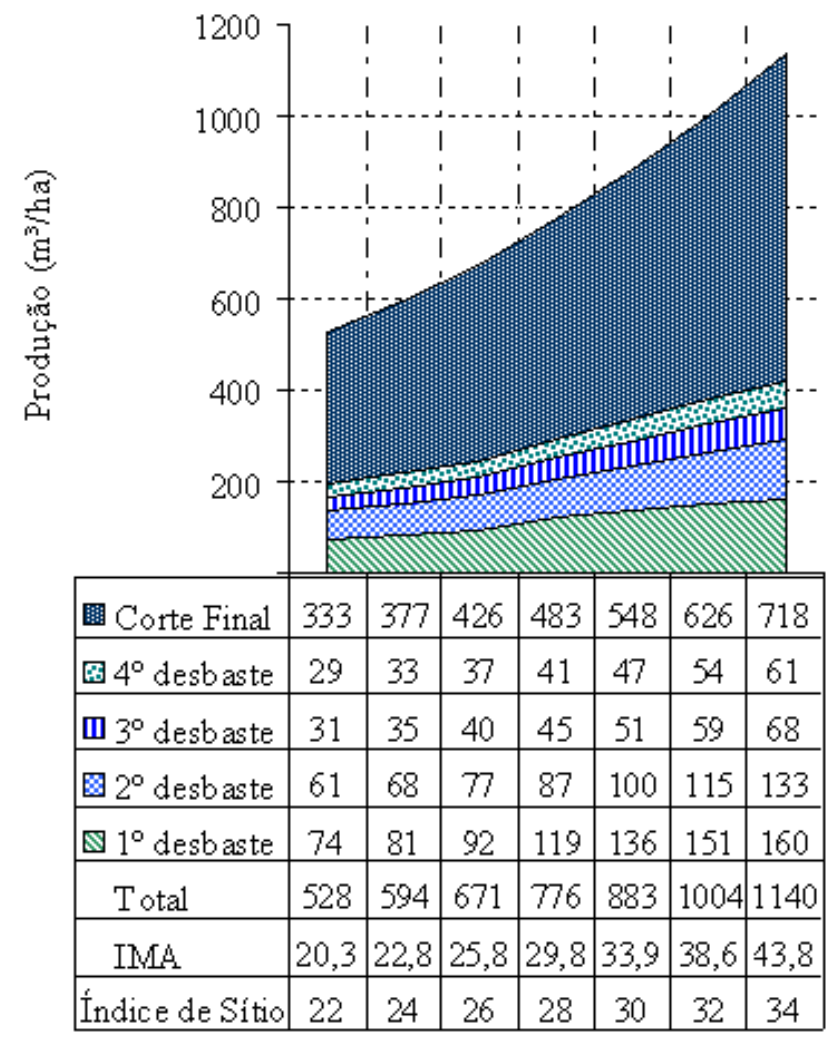

FIGURA 1: Produção por Índice de Sítio em cada corte nas idades de 10, 14, 18, 22 e 26 anos para povoamentos de Pinus elliottii na Serra do Sudeste, RS. Em que as unidades de medida usadas em cada linha de dados são: Corte Final, Desbastes e Total $\left(\mathrm{m}^{3} \cdot \mathrm{ha}^{-1}\right)$; IMA ou incremento médio anual em volume $\left(\mathrm{m}^{3} \cdot \mathrm{ha}^{-1} \cdot \mathrm{ano}^{-1}\right)$; Índice de Sítio, ou altura dominante na idade de 22 $\operatorname{anos}(\mathrm{m})$.

FIGURE 1: Yield by Site Index at each cut at age 10, 14, 18, 22, and 26 years for Pinus elliottii plantations at Serra do Sudeste, RS. Where measurement used units at each data lines are: Final Cut, Thinning, and Total $\left(\mathrm{m}^{3} \cdot \mathrm{ha}^{-1}\right)$. MAI or volume Mean Annual Increment $\left(\mathrm{m}^{3} \cdot \mathrm{ha}^{-1} \cdot \mathrm{year}^{-1}\right)$; Site Index, or dominant height at 22 years old (m).

\section{Análise econômica}

Os resultados da análise econômica da produção de madeira de Pinus elliottii na Serra do Sudeste são apresentados na Tabela 16.

O estudo do Valor Presente Líquido (VPL) resultou na constatação de que o investimento em projetos de Pinus na região deixa de ser negativo somente a partir Índice de Sítio (IS) 26. O IS 28 é o melhor encontrado nas florestas velhas, com mais de 20 anos, e fica pouco abaixo da média nas florestas novas, até os 15 anos de idade, servindo como um patamar básico para análise. Como o valor do arrendamento foi incluído no cálculo e o valor do VPL no IS 26 foi pequeno (R\$ 84,14), isso significa que em povoamentos com esse Índice de Sítio, a produção de madeira de Pinus tem rentabilidade um pouco maior do que o custo do arrendamento de terras, mesmo pagando juros de $6,75 \%$ a.a.

Partindo do IS 28, com VPL de R \$ 1.147,17/ha, a atividade passa a ser interessante, remunerando mais do que o custo do arrendamento. Como a produtividade média dos povoamentos mais antigos é pequena, se as condições tivessem permanecido as mesmas, poderia se considerar pouco atrativo plantar Pinus na Serra do Sudeste. Porém, com material genético melhorado, os povoamentos jovens vêm demonstrando que, aplicando tratos silviculturais e manejo adequados, a produtividade aumenta de forma considerável, podendo chegar a níveis muito superiores aos obtidos com as florestas mais velhas, mudando o panorama, tornando as florestas de Pinus altamente lucrativas. 
TABELA 16: VPL, Razão B/C, TIR e VAE da produção de madeira de Pinus na Serra do Sudeste, RS (2007).

TABLE 16: NPV, B/C ratio, IRR, and AEV of Pinus' wood production at Serra do Sudeste, RS (2007).

\begin{tabular}{|c|c|c|c|c|c|c|c|}
\hline \multirow{2}{*}{ Indicador } & \multicolumn{7}{|c|}{ Índice de Sítio } \\
\hline & 22 & 24 & 26 & 28 & 30 & 32 & 34 \\
\hline VPL (R $\$ / h a)$ & $-1.279,56$ & $-546,40$ & 84,14 & $1.147,17$ & $2.190,05$ & $3.417,50$ & $4.813,74$ \\
\hline Razão B/C & 0,74 & 0,89 & 1,02 & 1,23 & 1,45 & 1,70 & 1,98 \\
\hline TIR (\%) & 4,87 & 6,00 & 6,86 & 8,14 & 9,22 & 10,33 & 11,40 \\
\hline $\mathrm{VAE}(\mathrm{R} \$ / \mathrm{ha} / \mathrm{ano})$ & $-105,72$ & $-45,14$ & 6,95 & 94,78 & 180,94 & 282,35 & 397,70 \\
\hline
\end{tabular}

A razão Benefício/Custo ultrapassa a unidade nos povoamentos com IS 26, mostrando que somente começa a haver retorno dos investimentos nos povoamentos com produtividade acima desse patamar, ou seja, não há eficiência econômica abaixo do IS 26.

A Taxa Interna de Retorno (TIR) apresenta uma variação de aproximadamente 4,9\% no IS 22 até $11,4 \%$ no IS 34, verificando-se que somente partindo do IS 26 com uma TIR de $6,86 \%$ é possível remunerar os juros do PROPFLORA de 6,75\%, sendo inviável o cultivo de Pinus em sítios piores.

A TIR mostra que somente há retorno financeiro na produção de madeira de Pinus nas condições estudadas se o Índice de Sítio for 28 ou melhor. Assim, o silvicultor deverá escolher bem o material genético a utilizar, usar todas as técnicas silviculturais de eficácia já comprovada, como o sulcamento a 60 $\mathrm{cm}$ de profundidade e a eliminação da matocompetição até que as árvores plantadas suplantem a concorrência das ervas daninhas, com o objetivo de garantir que os plantios alcançarão os melhores índices possíveis de qualidade de sítio.

O Valor Anual Equivalente (VAE) mostra-se negativo nos Índices de Sítio 22 e 24, comprovando a inviabilidade da cultura nas condições estudadas em sítios dessa qualidade. Esse indicador passa a ser atrativo somente partindo do Índice de Sítio 26, mas a remuneração anual do capital empregado ainda é pequena (R\$ 6,95/ano). O Índice de Sítio 28, com um VAE de R\$94,78, é o primeiro que apresenta remuneração com alguma atratividade, semelhante ao mínimo valor do arrendamento de terras para pecuária na região, de $40 \mathrm{~kg}$ de boi vivo por hectare.

Nos plantios com a produtividade do Índice de Sítio 30 e acima, a remuneração do capital já é melhor do que o maior arrendamento de terras para pecuária na região que chega a $50 \mathrm{~kg}$ de boi vivo, ou cerca de R $\$ 120,00 \mathrm{ha}^{-1}$.ano ${ }^{-1}$. Assim, em projetos que precisam remunerar o capital para dar retorno financeiro aos investidores, a aplicação nessa atividade só é vantajosa a partir desse Índice de Sítio, pois abaixo disso seria preferível comprar terras e arrendar, sem ter qualquer tipo de trabalho e de risco.

Como se pode ver na Tabela 17, para o caso do Sítio 28 em que o VPL já se apresenta como atrativo, o VPL pode variar de R $\$-1.046,00$ com juros de $10 \%$ até $\mathrm{R} \$ 17.935,00$ com taxa de juros nula. A diferença no VPL, da taxa de juros de $0 \%$ para $6,75 \%$ a.a. (taxa do Propflora), é de R $\$ 16.788,00$, ou seja, os juros representam $93,6 \%$ da receita após descontadas as despesas. O produtor, de seus $6,4 \%$, ainda teria de separar uma parte para pagar os impostos que incidem sobre o faturamento e os lucros.

Na Tabela 17, observa-se ainda algo interessante: uma taxa de juros de 6\% no Índice de Sítio 28 resulta em Valor Anual Equivalente de R\$149,33, maior que o valor do arrendamento anual, indicando que essa deveria ser a taxa de juros máxima a ser praticada para que o cultivo de Pinus, nas condições estudadas, seja suficientemente atrativo com a produtividades no mínimo igual a desse Índice de Sítio.

TABELA 17: Efeito da taxa de juros sobre os indicadores econômicos no Índice de Sítio 28.

TABLE 17: Effects of interest rates on economic indicators at Site Index 28.

\begin{tabular}{|c|c|c|c|c|c|c|c|c|c|c|c|c|}
\hline \multirow{2}{*}{ Indicador } & \multicolumn{12}{|c|}{ Taxa de Juros } \\
\hline & $0,00 \%$ & $1,00 \%$ & $2,00 \%$ & $3,00 \%$ & $4,00 \%$ & $5,00 \%$ & $6,00 \%$ & $6,75 \%$ & $7,00 \%$ & $8,00 \%$ & $9,00 \%$ & $10,00 \%$ \\
\hline VPL (R\$) & 17935 & 13359 & 9815 & 7065 & 4924 & 3252 & 1942 & 1147 & 912 & 102 & -539 & -1046 \\
\hline VAE $(\mathrm{R} \$)$ & 690,02 & 586,05 & 487,82 & 395,22 & 308,09 & 226,21 & 149,33 & 94,78 & 77,16 & 9,39 & $-54,29$ & $-114,22$ \\
\hline $\mathrm{B} / \mathrm{C}$ & 3,48 & 2,99 & 2,57 & 2,20 & 1,88 & 1,61 & 1,38 & 1,23 & 1,19 & 1,02 & 0,88 & 0,76 \\
\hline
\end{tabular}

Como se vê, em povoamentos com o Índice de Sítio 28 , juros compostos acima de $6 \%$ são inviáveis para projetos tão longos quanto à silvicultura de Pinus elliottii em alto fuste com o objetivo de produção de 
madeira para serraria. O financiamento do Propflora é de até 12 anos, o que leva a crer que os responsáveis pelo programa têm consciência da incompatibilidade da taxa de juros para a produção de madeira em rotações longas. Cabe aos silvicultores tentar influenciar a mudança das políticas públicas para essa área, no sentido de criar programas de financiamento que possuam prazos e juros compatíveis.

\section{Rotação de máximo Valor Presente Líquido (VPL)}

O estudo do Valor Presente Líquido (VPL) foi realizado com o IS 28 e resultou na constatação de que o investimento em projetos de Pinus elliottii na região deixa de ser negativo somente a partir da rotação de 22 anos. O pior resultado financeiro é com rotação de 18 anos. O melhor resultado é da rotação de 26 anos e 4 desbastes, idade em que ocorreu o máximo VPL, como pode ser observado na Figura 2.

A partir da rotação de 22 anos e 3 desbastes, a atividade passa a ser interessante, remunerando o produtor em, no mínimo, $\mathrm{R} \$ 913,46 /$ ha ao final da rotação.

Deve-se fazer uma resalva quanto aos resultados: embora o VPL na rotação de 30 anos tenha sido menor do que na de 26 anos, não se considerou a viabilidade de venda de madeira mais grossa para tornearia por ainda não existir mercado regional para esse tipo de produto. O preço da madeira para tornearia ultrapassa o valor de $\mathrm{R} \$ 80,00 / \mathrm{m}^{3}$, o que pode tornar a rotação de 26 anos a mais lucrativa no futuro.

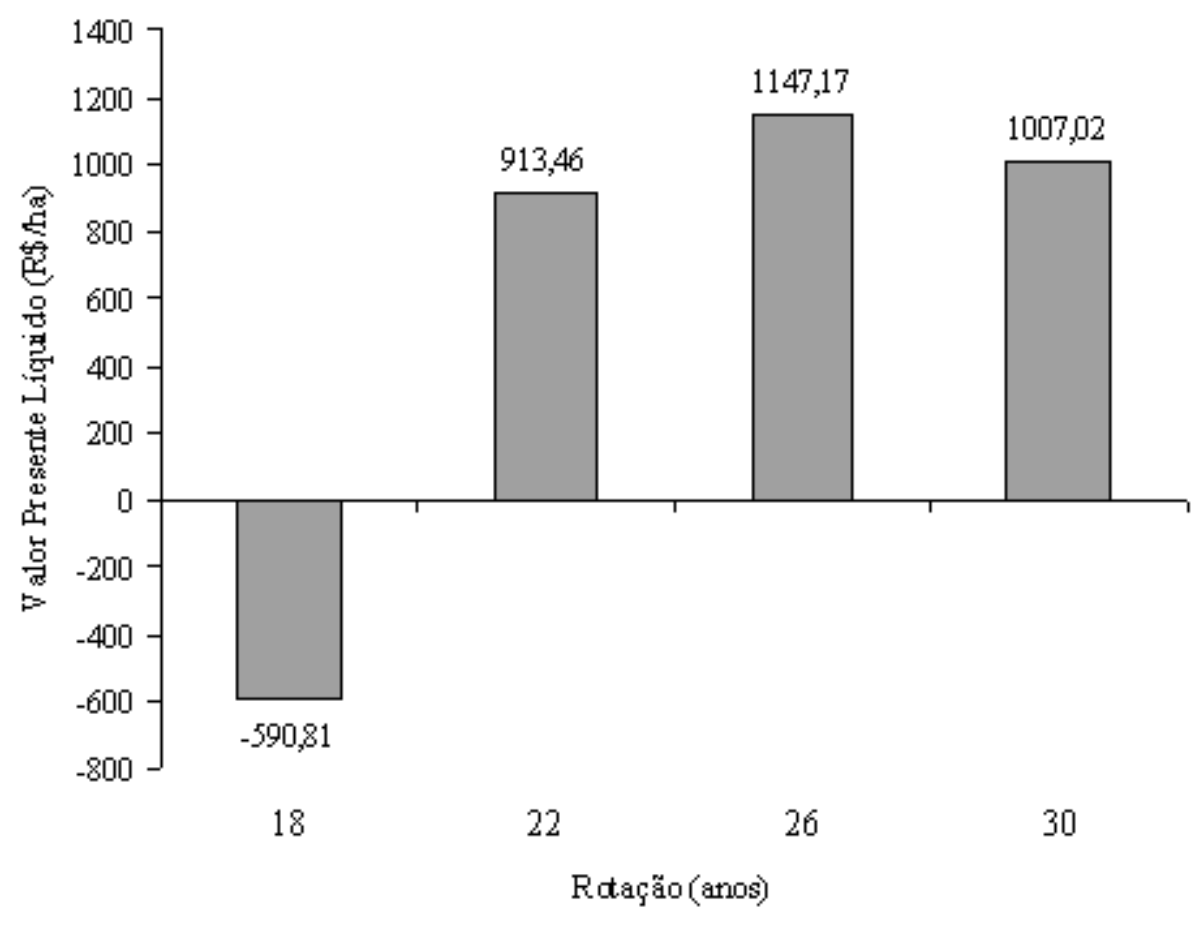

FIGURA 2: VPL com rotações de 18, 22, 26 e 30 anos, para Pinus elliottii na Serra do Sudeste, RS. FIGURE 2: NPV with rotation of 18, 22, 26, and 30 years, for Pinus elliottii at Serra do Sudeste, RS.

\section{CONCLUSÕES}

Os custos de implantação dos povoamentos foram estimados em R\$ 2.292,09/ha e os de manutenção anual variaram entre R \$ 134,84/ha e R \$ 363,98/ha.

Partindo do sítio 28, com VPL de R $\$ 1.147,17 /$ ha, a produção de madeira de Pinus passa a ser interessante, sendo que o no IS 26 , com uma TIR de $6,86 \%$, já seria possível remunerar os juros do Propflora de 6,75\%.

Dentro dos critérios de análise adotados, demonstrou-se que as taxas de juros oficiais e os prazos de pagamentos praticados no Brasil ainda são incompatíveis com a silvicultura de longa rotação, que tem como objetivo a obtenção de madeira de grandes dimensões e maior valor agregado, sendo necessário criar políticas governamentais adequadas e específicas para esse tipo de empreendimento. 
A análise de diferentes regimes de manejo para o IS 28 mostrou que o maior Valor Presente Líquido é obtido com rotação de 26 anos e quatro desbastes em ciclo de 4 anos, iniciando-se os cortes aos 10 anos.

A análise econômica foi realizada com bastante prudência, usando-se níveis de produtividade moderados, custos dentro de padrões que podem ser considerados entre médios e altos e preços de venda comedidos para o mercado de madeira atual. Mesmo com as restrições impostas à análise, os resultados para a silvicultura são promissores, sobretudo se for considerado que há uma forte tendência de aumento dos preços praticados pelo mercado regional e que há grande probabilidade de instalação de laminadoras de madeira para absorver os sortimentos de maior dimensão.

\section{REFERÊNCIAS BIBLIOGRÁFICAS}

ABIMCI. Dados Setoriais. Disponível em: <http://www.abimci.com.br/ dados_setoriais.html $>$. Acesso em: 23/12/2007.

ABRAF - Associação Brasileira de Produtores de Florestas Plantadas. Anuário estatístico da ABRAF: ano base 2005. Brasília, 2006. 80 p.

BOLETIM FLORESTAL. Custos do eucalipto destinado ao uso múltiplo. Boletim Florestal, s.l., a.1, n. 6, p. 2, dez. 2007.

BRDE. Florestamento na Região Sul do Brasil: uma análise econômica. [sl]: Banco Regional de Desenvolvimento do Extremo Sul - BRDE, Diretoria de Planejamento Superintendência de Planejamento, Departamento de Programas e Orçamento, 2003. $51 \mathrm{p}$.

CAIXA-RS. Notícias: CAIXA-RS lança Programa de Financiamento Florestal. Porto Alegre, 29/04/2004. Disponível em: $<$ http://www.caixa.rs.gov.br>. Acesso em: 14/05/2004.

CARVALHO, P. E. R. Espécies florestais brasileiras: recomendações silviculturais, potencialidades e uso da madeira. Colombo: EMBRAPA-CNPF / Brasília: EMBRAPA-SPI, 1994. 640 p.

DIÁRIO POPULAR, Editorial. Pelotas, 24/04/2004.

EMBRAPA-SOLOS. Mapa de solos do Brasil. Disponível em: <http://mapserver.cnps.embrapa.br/ website/pub/Brasil_Solos/viewer.htm>. Acesso em: 29/11/2006.

FAO. State of the World's Forests 2007. Rome, 2007. 144 p.

FLORIANO, E. P. Subsídios para o planejamento da produção de Pinus elliottii Engelm. na Serra do Sudeste, Rio Grande do Sul. 2008. $178 \mathrm{f}$ f. Tese (doutorado) - Universidade Federal de Santa Maria, Santa Maria.

IMAFLORA/SMARTWOOD. Resumo Público de Certificação FSC Programa SmartWood de Suzano Bahia Sul Papel e Celulose SA (Certificado: SW-FM/COC-1377). Mucuri, 2004. 50 p.

JOVEM SUL NEWS. Agricultura: Eucalipto como opção agroflorestal na região. Chapadão do Sul, MS, 11/02/2006 às 17:55:00 hs. Disponível em: <http://www.jovemsulnews.com.br/user/ index.php?id=15846>. Acesso em: 23/12/2007.

MI - MINISTÉRIO DA INTEGRAÇÃO NACIONAL. Ação conjunta definirá prioridades para o desenvolvimento da Metade Sul. Brasília: Ministério da Integração Nacional, 03/07/2003. Disponível em: $<\mathrm{http}: / /$ www.integracao.gov.br/comunicacao/noticias/noticia.asp?id=181>. Acesso em: 3/11/2007.

REZENDE, J. L. P. Curso de análise econômica de projetos florestais. Santa Maria: UFSM, 2005.

SBS. Fatos e números do Brasil florestal. São Paulo, 2006. 106 p.

WILLIAMS, M. R. W. Decision-making in forest management, 2nd ed. Great Yarmouth: Research Studies Press/John Wiley \& Sons, 1988. 